\title{
How Swap Execution Facilities will Reshape the OTC Derivative Swap Market
}

\section{Fabio Faltoni ${ }^{1}$ and Cesario Mateus ${ }^{2 *}$}

${ }^{1}$ Grenoble School of Management, France

${ }^{2}$ University of Greenwich, UK

\section{Introduction}

There was much of pointing fingers in the wake of the 2008 Global Financial Crisis. Economists, politicians and the financial industry itself dwelled to assign blame to what is considered to be the most damaging economic crisis since the 1930s Great Depression. Undoubtedly, the over-counter- derivatives market has been target for criticism on different fronts and cast into the limelight. Ruthless press articles condemning OTC instruments only helped to fuel the rage and social discontent of the thousands of unemployed that emerged after the crash, while regulators and policy makers seized the opportunity to publicly express their disapproval by sentencing the alleged opaqueness and complexity of derivative products, while they themselves were the ones who pushed for de-regulation and less stringent market oversight of what were back then considered "innovative products and good for society".

It would only be a matter of time before The Commodity Futures Modernization Act of 2000 (CFMA) would cease to exist, or at least considerably redrafted. To those less familiar with the legal world, the law is what officially guaranteed a modernized regulation of OTC derivative products. Signed into law on December 21, 2000 by President Bill Clinton, it exempted over-the-counter derivatives transactions between "sophisticated parties" from being regulated "futures" under the Commodity Exchange Act of 1936 (CEA) or as "securities" under the federal securities laws [1]. Instead, they would be would continue to only be accountable to the "Safety and Soundness" standards, which it goes without saying, are by far less restrictive and stringent than the other two. As a result, the OTC swap market exponentially became less transparent than exchange traded products. The lack of clarity of what was happening behind the scenes among the major banks, the so called "sophisticated parties" is by many considered the main reason of why 2008 will be remembered as the year the world fell apart in all economic text books yet to be published. AIG's collapse in September 2008 is perhaps the epitome in its purest essence of why transparency was a core issue that had to be addressed. While filing for bankruptcy, no one exactly knew to whom all of AIG's contracts actually belonged to; who the counterparties were and how those products were priced and valued. "Prices were murky and risk was interlinked" said Nathan Jenner, COO of Fixed Income E- Trading at Bloomberg. Uncertainty soon became the watchword across the entire financial sector.

\section{Swap Execution Facilities}

Enclosed in the Dodd-Frank Act, the Wall Street Transparency and Accountability Act of 2010, or more commonly referred to as Title VII, is the nucleus leading the change, including the change in favor of electronic execution. By giving jurisdiction over swaps (derivatives tied to commodities or interest rates) to the Commodities Futures Trading Commission (CFTC) and jurisdiction over security- based swaps (derivatives tied to the performance of securities or loans) to the Securities and Exchange Commission (SEC), Title VII established a completely new comprehensive regulatory framework for swaps and security-based swaps. It addresses the hitherto opaque and unregulated over the counter derivatives market with the intention of rendering it more financially stable and more transparent. One of the key goals of
Title VII is to bring greater pre-trade and post-trade transparency to the swap market. With respect to the swap market, the former refers to accurately indicating every information relevant for prospective trading interest including the bid/ask spread and quantity available at those prices. On a similar line, post-trade transparency refers to providing the trade details after the completion of every swap transaction [2].

Advocates of greater transparency argue that by making markets more competitive and accessible, have a positive knock on effects on lowering costs for investors, reducing the risk inherent in the swap market and ultimately provide greater protection to market participants due to enhanced market integrity. On the other hand however, there is a non-indifferent mass opposing to this logic arguing that, especially in the context of institutional markets where trades are infrequent but large in size, greater transparency may increase market impact of trades leading to greater execution costs. It is important to understand the means through which regulators intend to bring transparency to a sector which since its origin has been characterized by opacity and been outside of the regulators domain. This brings us back to our two famous words "electronic execution". Title VII of the Dodd-Frank Act establishes a comprehensive regulatory framework outlining the registration, operation and compliance Swap Execution Facilities have to comply with. Title VII defines a Swap Execution Facility (SEF) as a "trading system or platform in which multiple participants have the ability to execute or trade swaps by accepting bids and offers made by multiple participants in the facility or system and is not a designated contract market".

Swap Execution facilities are the platforms through which electronic execution of swap contracts will take place and the means through which regulators intend to bring more pre/post-trade transparency in the OTC swap market. They are the clearest example of a many-to-many execution model which strongly opposes to what was until now the normal way of conducting business i.e. though a oneto-many (single dealer) platform, where the sponsoring entity will be the only liquidity provider to all other counterparties. In broad terms, these provisions will essentially divide the OTC derivatives market into two. The "Non-standard" trades or trades involving a corporate end user will continue to be executed as before i.e. through bilateral agreements between the two entities which will ultimately report to a clearinghouse. However, the story is quite different for all clearing eligible products involving financial entities. Such instruments will be required to trade on SEFs. This has given birth to a slightly more complex trade reporting ecosystem.

*Corresponding author: Mateus C, University of Greenwich, UK, Tel: +44 20 8331 9000; E-mail: C.Mateus@greenwich.ac.uk

Received June 10, 2015; Accepted July 29, 2015; Published August 06, 2015

Citation: Faltoni F, Mateus C (2015) How Swap Execution Facilities will Reshape the OTC Derivative Swap Market. J Stock Forex Trad 4: 154. doi:10.4172/21689458.1000154

Copyright: @ 2015 Faltoni F, et al. This is an open-access article distributed under the terms of the Creative Commons Attribution License, which permits unrestricted use, distribution, and reproduction in any medium, provided the original author and source are credited. 
Title VIII Section 2(h)(8) states that without any exception, "any person operating a platform in which more than one market participant has the ability to execute or trade swaps with more than one other market participant must register either as a SEF unless it is registered as a DCM (Designated Contract Market)". But when did all of this become mandatory? As mentioned earlier, Title VII establishes a comprehensive regulatory framework outlining the registration, operation and compliance Swap Execution Facilities have to comply with. It wasn't until May 16th 2013, that the CFTC finalized its set of guidance and principles applying to the functioning and operation of Swap execution facilities. The key dates are the following:

October $2^{\text {nd }}, 2$ 2013: By this date, all participant platforms were required to finalize and submit their application to become a regulated Swap Execution Facility, operate per the SEF rules once approved and comply with certain swap data repository (SDR) derivatives reporting obligations in case any swap transactions took place in its facility. This is because as of this date, SEF trading was still not mandatory as no swaps were 'Made available to trade' (MAT) yet.

February $15^{\text {th }}, 2014$ : Date which market the beginning for certain types of swaps to be mandatorily traded of SEFs. As of April 15, 2014 a subset of IRS Fixed-Float swap and untranched CDX made available to trade so far. Any transaction involving a swap that is required to mandatorily be cleared must be executed on a Swap Execution Facility or DCM unless either that particular type of swap is exonerated form any pre-established clearing requirements or neither a SEF or DCM require the swap to be made available to trade (MAT).

\section{Swap Execution Facilities, Credit Default Swaps and Volume}

Credit Default Swaps is one of the asset classes which have been affected by the regulatory reforms. Only four types of CDS products have been classified as Made Available to Trade (MAT). As shown in the Figure 1 below there has been a drastic fall in volumes for all of the four MAT products around the key dates. More precisely, as shown volumes in the month of October 2103 have collapsed by $19 \%$ with respect to the previous month followed by a $37 \%$ and $20 \%$ drops in the months of November and December, respectively. A similar although less accentuated trend took place after February 2015, date of the MAT. In fact, in the month of February volumes dropped by $21 \%$ before recovering their losses in March [3].

The percentage volume drop around these key dates is by far more accentuated than in any other period (Figure 2). In fact, the percentage volume swings for the other months are quite stable. This is true with the exception of October 2014 onwards where volumes fell by $63 \%$ between October and November before recovering a quarter of the loss in December. Interestingly enough, there was neither announcement nor any new rules entering into force which were specifically related to SEFs. The anomaly in volumes starting from September 2014 is most likely a direct result of a change, or at least an "expected change" in the macroeconomic stance of the US. With the general consensus being that the FED would increase interest rates around the second half of 2015, interest rate volatility sharply increase leading to market participants to hedge or re-position their portfolios hence explaining the steep increase in volumes. From the same graph it is also possible to observe that the linear trend line (trend downwards).

Although the steepness of the curve is nearly flat, this is an indicator that all in all, volumes of MAT products are slowly diminishing [4] However, this does not seem to be the case for Non-MAT products (Figure 3). In fact, the combined moving average is trending in the opposite direction. Non- MAT products also seem to behave in the opposite way to MAT products on the first SEF critical date. In October, volumes actually increased by $28 \%$ with respect to September, followed by a $12 \%$ and $8 \%$ rise in the months of November and December respectively. The behavior is however similar for the MAT implementation period. Volumes dropped $12 \%$ in Feb with a further decline of $18 \%$ in March.

A similar story is reflected in the percentage change in the number of monthly trades. Figure 4 clearly shows that with the exception of the November/December 2014 anomaly, trade count volumes have dropped the most after each of the two critical dates. In fact, for October 2013, the number of trades for MAT products dropped by $43 \%$ with respect to September, while Non-MAT product volumes fell by $30 \%$. Likewise, volumes decreased by $32 \%$ and $23 \%$ during February 2014 for MAT and Non-MAT products respectively. However, gross notional volumes and trade count volumes have not been the only two parameters which have been decreasing on a consistent basis since the introduction of SEFs [5].

In fact, and perhaps what is even more worrying, is the persistent decline in the average trade size for MAT products trade on SEFs. Equally interesting, as reported in Figures 5 and 6, is the fact that the average monthly trade size for MAT products traded on-SEFs has always been lower in comparison to MAT products traded off-SEFs

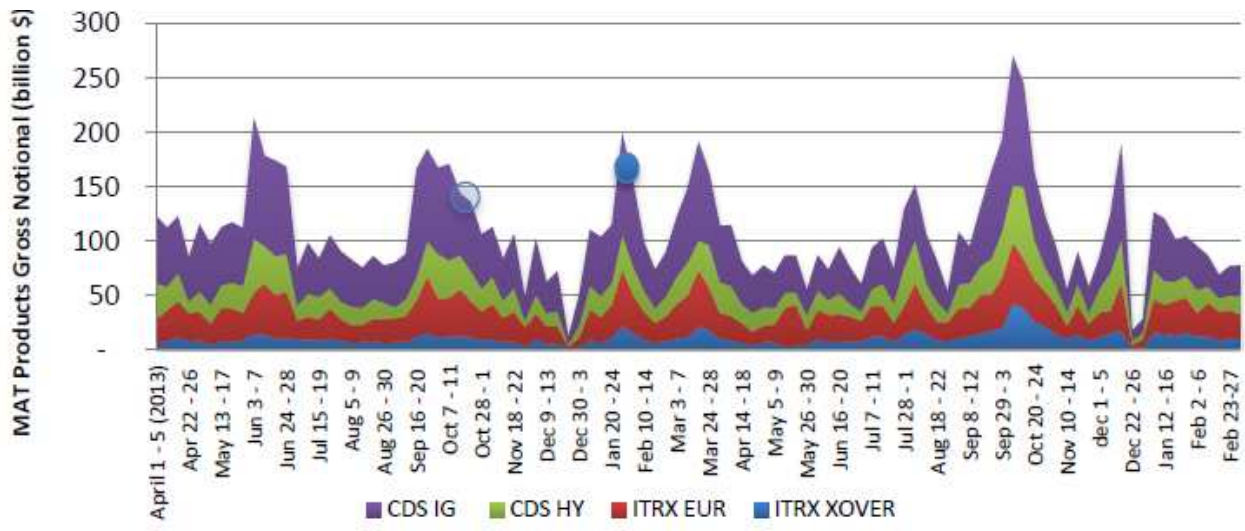

Source: Authors calculations from Bloomberg.

Figure 1: Individual MAT Gross Notional Weekly Volume (\$ Billion). 
Citation: Faltoni F, Mateus C (2015) How Swap Execution Facilities will Reshape the OTC Derivative Swap Market. J Stock Forex Trad 4: 154. doi:10.4172/2168-9458.1000154

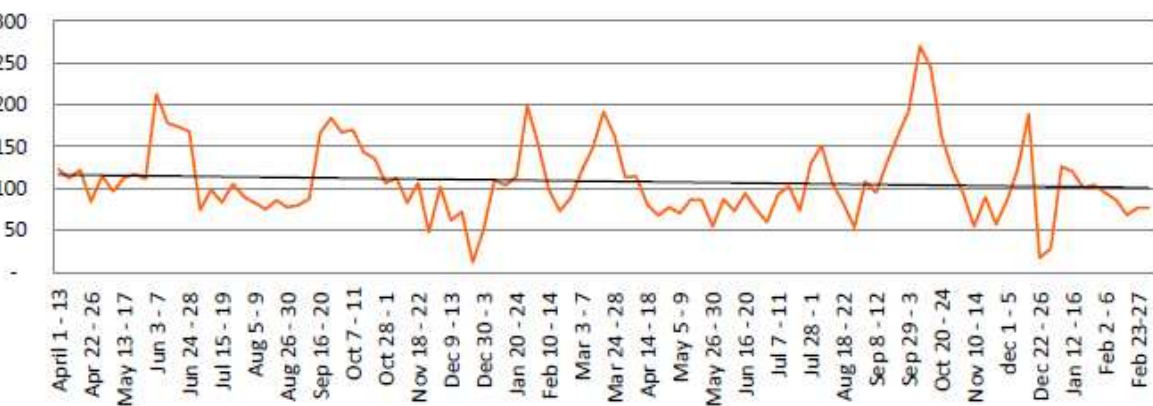

MAT Products

- Linear (MAT Products)

Source: Authors calculations from Bloomberg.

Figure 2: Aggregate MAT Gross Notional Weekly Volume (\$ Billion)

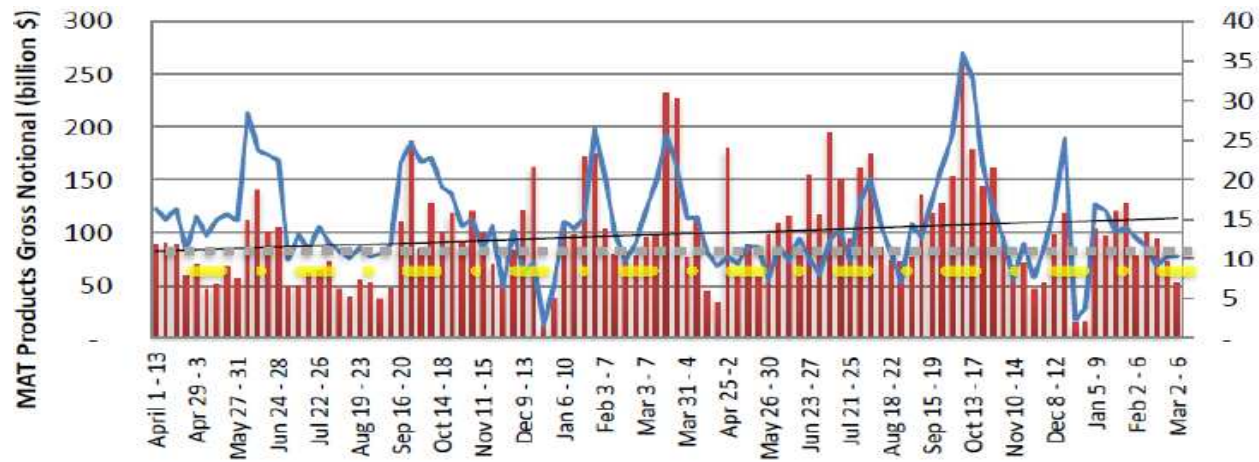

Source: Authors calculations from Bloomberg.

Figure 3: MAT and non-MAT Gross national weekly volume (\$Billion).

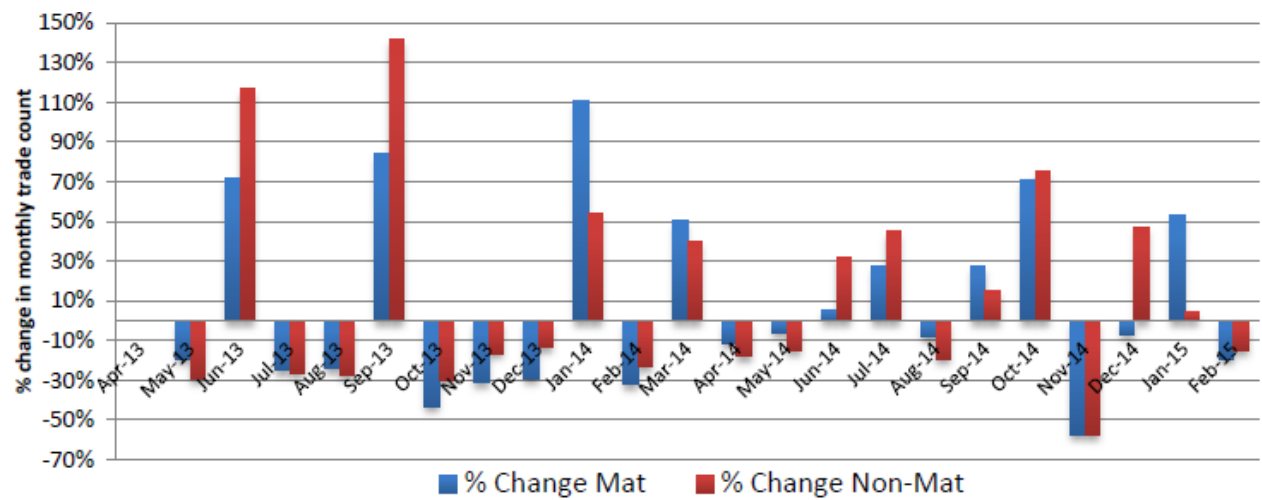

Figure 4: Percentage change in monthly trade counts for MAT andnon-MATproducts.

(this is actually a good indicator of how greater transparency may be detrimental to liquidity and in particular to trade sizes).

\section{Conclusion}

In the wake of the recent financial crisis, derivative markets have been cast into the limelight, often because of regulators and policy maker's criticism regarding the alleged opaqueness and complexity of derivative products and their contribution to potential sources of heightened volatility and systemic risk. As a result, a multitude of reforms and changes have been implemented across different regions, which however have often been criticized as being excessive and detrimental to market functionality [6]. One of these cornerstone reforms, and perhaps the centerpiece to this short communication, is the introduction of swap Execution Facilities (SEFs); regulated 
Citation: Faltoni F, Mateus C (2015) How Swap Execution Facilities will Reshape the OTC Derivative Swap Market. J Stock Forex Trad 4: 154. doi:10.4172/2168-9458.1000154

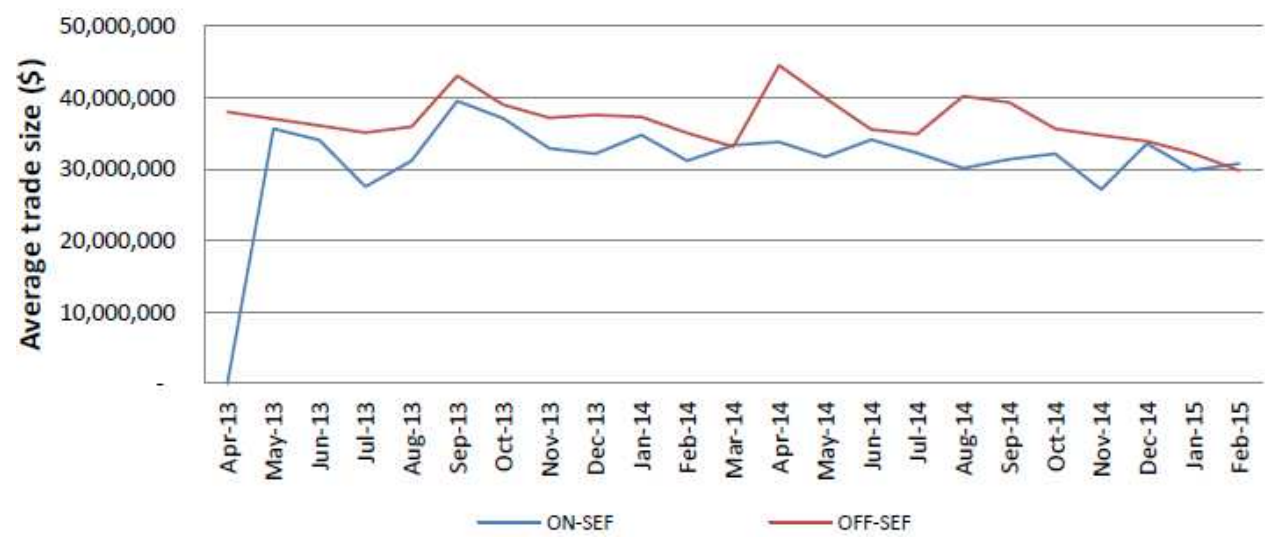

Source: Authors calculations from Bloomberg.

Figure 5: Average monthly trade size for MAT products.

Source: Authors calculations from Bloomberg

Figure 6: Average trade size for non-Mat products

platforms for OTC swap trading, that demand certain standardized swap products to be executed on a multilateral venue as opposed to being traded privately between two parties and far from any regulated exchange as it used to be in the past. SEFs are one of the key chapters in the Dodd- Frank Wall Street Reform and Consumer Act of 2010, a landmark financial reform bill passed as a response to the recent Financial Crisis. Analyzing and evaluating the impact of Swap Execution Facilities have in the OTC derivative market, in particular focusing on how market transparency and market liquidity have changed after their introduction on February 15, 2014 is of major importance. Preliminary analysis shows a gross notional volumes and trade count volumes decline and persistent drop in the average trade size for MAT products trade on SEFs. This is indeed a good indicator of how greater transparency may be detrimental to liquidity and in particular to trade sizes. Further compressive research is required to tackle two different but interrelated issues. The former is to try to understand whether the introduction of Swap Execution Facilities is increasing transparency in the opaque over the counter derivative market. The second should focus on analyzing whether SEFs are having any relevant impact on market liquidity.

\section{References}

1. Core principles and other requirements for swap execution facilities, Commodity Futures Trading Commission Office of Public Affairs, Washington.
2. (2011) Costs and Benefits of Mandatory Electronic Execution Requirements for Interest Rate Products ISDA and NERA Economic Consulting, USA.

3. Duering A, Harvey O (2014) How regulation will reshape FX and Rate Markets Deutsche Bank Markets Research.

4. (1999) HR 5.660-Commodity Futures Modernization Act of 2000, The Library of Congress.

5. Malyshev P, Ammons J, Dilworth R, Ackerman B (2013) Swap execution facilities launch in 2013 but Many Issues Remain for 2014 Futures and Derivatives Law Report 33.

6. Paulson R, Paulsen M, Penner W, Berman S, Thompson E (2013) FS Regulatory Brief Derivatives SEFs - Opening Bell Sounds. Price water house Coopers Regulatory. 